\title{
Proteome Changes in Caco-2 Cells Treated with Monascus-Fermented Red Mold Rice Extract
}

\author{
Wun-Yuan Lin, ${ }^{\dagger}$ Wei-Yi Hsu ${ }^{\dagger}$ Chin-Hsuan Hish, ${ }^{\dagger}$ And Tzu-Ming Pan ${ }^{*}, *$ \\ Department of Food Science, Nutrition, and Nutraceutical Biotechnology, Shih Chien University, and \\ Institute of Microbiology and Biochemistry, National Taiwan University,
}

Taipei, Taiwan, Republic of China

\begin{abstract}
Monascus-fermented red mold rice has been extensively used as a folk medicine for thousands of years. Monascus secondary metabolites, including monacolin K, monascorubrin, and ankaflavin, have been reported to have an antiproliferative effect on cancer cells. However, the cell machinery responsible for the antiproliferation of Monascus-fermented red mold rice treatment in cancer cells remains unclear. A proteomic approach using two-dimensional gel electrophoresis, matrix-assisted laser desorption ionization time-of-flight/time-of-flight mass spectrometry, and tandem mass spectrometry was used to identify proteins with modified expression in Caco-2 cells treated with Monascusfermented red mold rice extract. A total of 20 proteins were identified with significantly altered expression $(P<0.05)$ in response to Monascus-fermented red mold rice extract treatment. The deregulated proteins that were identified included heat shock protein 70 , protein kinase $C \varepsilon$ type, clusterin-associated protein 1 , and two tumor suppressors ( $\mathrm{N}$-chimaerin and calponin-2). Our results suggested the involvement of heat shock protein 70-mediated cytotoxicity in the Caco-2 cells treated with Monascus-fermented red mold rice extract.
\end{abstract}

KEYWORDS: Monascus; polyketides; anticancer; protein extraction; proteomics

\section{INTRODUCTION}

Monascus-fermented red mold rice has been extensively used as a fermented food and folk medicine for thousands of years in China. Monascus produces many types of polyketide secondary metabolites, which have an enormous commercial value and many functional properties, including a group of yellow pigments, ankaflavin and monascin, orange pigments, monascorubrin and rubropunctatin, red pigments, monascorubramine and rubropunctamine (1), monacolin $\mathrm{K}$, and the antibacterial compound citrinin $(2,3)$. There are many scientific reports on the medical or functional food effects of Monascus-fermented red mold rice (4). Clinical observations now clearly show that Monascus-fermented red mold rice has the ability to lower blood lipid levels in animal models and in humans (5). Monacolin K (MK, an analogue of lovastatin and mevinolin) is a competitive inhibitor of 3-hydroxy-3-methylglutaryl coenzyme A (HMG$\mathrm{CoA})$ reductase that reduces the rate of cholesterol synthesis by blocking the conversion of HMG-CoA to mevalonate (2). Additionally, it inhibits the synthesis of other products downstream from mevalonate. Pools of mevalonate-derived products, such as farnesyl diphosphate, geranylgeranyl diphosphate, and dolichyl phosphate, are essential for the post-translational modification and biological activity of diverse proteins that have

* To whom correspondence should be addressed. Telephone: $+886-$ 2-3366-4519. Fax: +886-2-2362-7044. E-mail: tmpan@ntu.edu.tw.

${ }^{\dagger}$ Shih Chien University.

\$ational Taiwan University. roles in cell growth (6). Prenylation of small GTP-binding proteins, such as the Ras superfamily proteins, with farnesyl or geranylgeranyl groups is required for their translocation to the plasma membrane and function (7). Translocation of small GTPbinding proteins is related to cell survival, proliferation, and differentiation (8).

On the other hand, some lovastatin-mediated effects involving the complete independence of HMG-CoA reductase have been reported (9). In addition, orange pigment monascorubrin has been reported to affect suppression of tumor promotion induced by $12-O$-tetradecanoylphorbol 13 -acetate and followed by initiation with 7,12-dimethylbenz $[a]$ anthracene in mice (10). Interestingly, yellow pigment from Monascus-fermented red mold rice, ankaflavin, was recently reported to have a cytotoxic effect on the human cancer cell line Hep G2 (11). However, the use of natural food dietary agents has been increasingly appreciated in recent years as an effective way to manage many cancer types in an approach known as cancer chemoprevention. The fact that Monascus-fermented red mold rice, which is reported to contain many active components that block tumor cell proliferation, including MK (12), monascorubrin (10), and ankaflavin (11), may be used as a natural anticancer agent makes it more suited to development as a functional health food. However, the overall view of the cell machinery in tumor cells in response to Monascus-fermented red mold rice treatment has not yet been reported. Proteomics allows the profiling of the expression patterns of the proteins of an entire cell involved in metabolic pathways and also helps to directly discern the biology 
of cells at the protein species level and the protein composition changes under different conditions.

The objective of this work was to use proteomic analysis to identify the proteins of Caco- 2 colorectal adenocarcinoma cells treated with Monascus-fermented red mold rice extract (MRE) and examine the altered protein profiles associated with the MRE-induced antiproliferation. Our resulting data revealed a number of tumor-related proteins that showed changes in expression under the MRE treatment and indicated the involvement of heat shock protein 70-mediated cytotoxicity in the MRE-treated Caco-2 cells.

\section{MATERIALS AND METHODS}

Cell Culture. The human colorectal adenocarcinoma cells, the Caco-2 cell line (BCRC 60182), were obtained from the Bioresource Collection and Research Center (BCRC) in Taiwan and were cultured in minimal essential medium (MEM) (Gibco BRL, Grand Island, NY) supplemented with $10 \%$ fetal bovine serum (Biochrom AG, Berlin, Germany), $44 \mathrm{mM}$ sodium bicarbonate (Sigma), 100 units $/ \mathrm{mL}$ penicillin, and $100 \mu \mathrm{g} / \mathrm{mL}$ streptomycin (Gibco BRL) at $37{ }^{\circ} \mathrm{C}$ under $5 \% \mathrm{CO}_{2}$ and $95 \%$ air. For treatment with MK and MRE, cells were cultured in MEM until nearly confluent. Medium was removed and replaced with a medium containing either the solvent dimethyl sulfoxide (DMSO) or various concentrations of MK and MRE (solubilized in DMSO). Cells were then harvested at the times stated in the figure legends.

Reagents and Materials. The two-dimensional electrophoresis reagents, including acrylamide solution (25\%), urea, thiourea, 3-[(3cholamidopropyl)dimethylammonio]-1-propanesulfonate (CHAPS), dithiothreitol (DTT), Immobilline Dry Strips, immobilized pH gradient (IPG) buffer, IPG cover mineral oil, Tris base, sodium dodecyl sulfate (SDS), iodoacetamide (IAA), trifluoroacetic acid (TFA), and the protein assay kit were purchased from Bio-Rad (Hercules, CA). Monacolin K (MK), 3-(4,5-dimethylthiazol-2-yl)-2,5-diphenyltetrazolium bromide (MTT), DMSO, and $\alpha$-cyano-4-hydroxycinnamic acid (CHCA) were purchased from Sigma (St. Louis, MO). Sypro Ruby stain was purchased from Amersham Biosciences (Piscataway, NJ). Trypsin (modified) was obtained from Promega (Madison, WI). Other reagents used in this work were of analytical grade and purchased from local suppliers.

Preparation of MRE and Determination of MK, Ankaflavin, and Monascorubrin Concentrations. Powdered Monascus-fermented red mold rice was obtained from WeiChuan Bio-Tech Co. (Taipei, Taiwan). The $20 \mathrm{~g}$ sample was soaked in $100 \mathrm{~mL}$ of methanol at $30{ }^{\circ} \mathrm{C}$ for 3 days. The sample was filtered with filter paper (Advantec No. 1) while the residue was further extracted twice more under the same conditions. The filtrates collected from three separate extractions were combined and then centrifuged at $3000 \mathrm{~g}$ for $10 \mathrm{~min}$, followed by filtration through a $0.25 \mu \mathrm{m}$ pore size filter, and evaporated to dryness under a vacuum to give a yield of $600 \mathrm{mg}$ of MRE. The assay of MK concentration in the MRE was performed using the previously described HPLC method (13) and carried out on a HPLC PU2089 plus system (Jasco Co., Tokyo, Japan) [Discovery (Bellefonte, PA) C18 column, $25 \mathrm{~cm} \times 4.6 \mathrm{~mm}$ (inside diameter), $5 \mu \mathrm{m}$; mobile phase, water/acetonitrile $(45: 55, \mathrm{v} / \mathrm{v})$ and $0.5 \%$ (v/v) TFA; flow rate, $1.0 \mathrm{~mL} / \mathrm{min}$; detector, UV $238 \mathrm{~nm}$ ]. The measurements of concentrations of the pigment ankaflavin and monascorubrin in the MRE were carried out using the HPLC method as previously described (14).

MTT Reduction and DNA Fragmentation Assay. The antiproliferative effects of MK and MRE against Caco-2 cells were measured using a MTT reduction assay (12). Briefly, Caco- 2 cells $\left(1 \times 10^{5}\right.$ cells/ $\mathrm{mL}$ ) were seeded in triplicate in 96-well microtiter plates. Cells were treated with various levels of MK $(1-100 \mu \mathrm{M})$ and MRE (containing 1-100 $\mu \mathrm{M} \mathrm{MK)} \mathrm{for} 24 \mathrm{~h}$. Thereafter, $50 \mu \mathrm{L}$ of a MTT solution [1 $\mathrm{mg} / \mathrm{mL}$ in phosphate-buffered saline (PBS)] was added to each well followed by incubation for $4 \mathrm{~h}$ at $37^{\circ} \mathrm{C}$. The MTT solution in the medium was removed via aspiration. After solubilization of the purpleblue MTT formazan crystal formed in viable cells by incubation of the cells overnight, $200 \mu \mathrm{L}$ of DMSO was added to each well. The absorbance of the solution was measured at $595 \mathrm{~nm}$, using a microplate reader and a microtiter plate ELISA reader (MRX-reader, DYNEX
Technologies, Chantilly, VA) with DMSO as the blank. The DNA ladder was detected by agarose gel electrophoresis. Caco- 2 cells $(1 \times$ $10^{5}$ cells $\left./ \mathrm{mL}\right)$ were treated with MK $(25$ and $75 \mu \mathrm{M})$ and MRE (containing $75 \mu \mathrm{M} \mathrm{MK}$ ) for $24 \mathrm{~h}$. Cells were washed with PBS and resuspended in lysis buffer [1 mM EDTA, $10 \mathrm{mM}$ Tris ( $\mathrm{pH} 8.0), 1 \%$ SDS, and $1 \mathrm{mg} / \mathrm{mL}$ proteinase $\mathrm{K}$ ]. After incubation for $1 \mathrm{~h}$ at $37^{\circ} \mathrm{C}$, RNase A (Sigma) was added and incubation continued for $1 \mathrm{~h}$. Crude DNA preparations were extracted twice with a phenol/chloroform/ isoamyl alcohol (25:24:1) mixture. Cell lysate samples were subsequently run at $100 \mathrm{~V}$ for $1 \mathrm{~h}$ on a $1.5 \%$ agarose gel containing $1 \mu \mathrm{g} /$ $\mathrm{mL}$ ethidium bromide (Sigma). The gel was examined on an ultraviolet light source and photographed. DNA fragmentation analysis was performed in triplicate with essentially the same results.

Protein Extraction, Subcellular Fractionation, and 2-DE Analysis. The cells derived from the untreated control and MRE (containing $50 \mu \mathrm{M} \mathrm{MK}$ ) treatment for $24 \mathrm{~h}$ were trypsinized and washed with PBS buffer. Subcellular fractionation was performed using the Compartment Protein Extraction Kit (BioChain Institute, Hayward, CA). The cells were homogenized at moderate speed twice. Following the fractionation protocol, $2 \mathrm{~mL}$ of ice cold Biochain cytoplasmic fraction-enriched buffer was added to $1 \mathrm{~g}$ of homogenate suspension, and the suspension was homogenized twice. After centrifugation at $4{ }^{\circ} \mathrm{C}$ and $11000 \mathrm{~g}$ for 20 min, the cytoplasmic fraction-enriched proteins were collected in the supernatant. The pellet was washed with ice cold Biochain wash buffer twice. The previous steps were repeated with ice cold Biochain membrane fraction-enriched buffer to collect the membrane fractionenriched proteins in the supernatant. Protein content was determined by the Bradford method (protein assay kit, from Bio-Rad). 2-DE (13 $\mathrm{cm}, \mathrm{pH} 4-7$, nonlinear) was assessed with Amersham Biosystems IPGphor IEF and Ettan Dalt six electrophoresis units by following the protocol described previously (15). The dried IPG strips were actively rehydrated with the loading of protein samples $(300 \mu \mathrm{g} / 350 \mu \mathrm{L})$ at 10 $\mathrm{V}$ for $10 \mathrm{~h}$ at $20{ }^{\circ} \mathrm{C}$ in the ceramic strip holder. IEF was carried out with the following conditions: step 1 (rehydration), $10 \mathrm{~V}$ for $12 \mathrm{~h}$; step 2, $100 \mathrm{~V}$ for $1 \mathrm{~h}$; step 3, $250 \mathrm{~V}$ for $1 \mathrm{~h}$; step 4, $500 \mathrm{~V}$ for $1 \mathrm{~h}$; step 5, $1000 \mathrm{~V}$ for $1 \mathrm{~h}$; step $6,4000 \mathrm{~V}$ for $1 \mathrm{~h}$; step 7, $8000 \mathrm{~V}$ for $45 \mathrm{kVh}$; total $50975 \mathrm{~V} / \mathrm{h}$. The focused IPG strips were equilibrated with equilibration buffer [50 mM Tris ( $\mathrm{pH} 8.8$ ), $6 \mathrm{M}$ urea, $30 \%$ (v/v) glycerol, $2 \%(\mathrm{w} / \mathrm{v})$ SDS, and 2\% (w/v) DTT] three times for 10 min each and then resolved on vertical SDS-PAGE gels. 2-DE was run in pairs side by side and performed in triplicate for each pair of samples to ensure reproducibility.

Tryptic In-Gel Digestion of 2-DE Spots. Sypro Ruby stain was used for visualization of the 2-DE gel. The fluorescently stained 2-DE gel was digitally scanned as a 2-DE image on the Typhoon 9200 fluorescence image scanner (Amersham Biosciences). Spot detection, quantification, and matching were managed using PDQuest (Bio-Rad). 2-DE gel data were normalized by dividing each spot quantity by the total quantity of all of the valid spots in the 2-DE gel image to obtain a normalized spot quantity value. For each matched spot, the mean of the three quantity values from triplicate 2-DE gels was calculated. The differences in protein expression between the control and treated group were considered statistically significant at $P<0.05$ in Student's $t$ test. The gel spots were excised from the gels using biopsy punches. Proteins selected for analysis were in-gel reduced, alkylated, and digested with trypsin. Briefly, spots were washed twice with water, shrunk for 15 min with $50 \%(\mathrm{v} / \mathrm{v}) \mathrm{ACN}$, and dried in a vacuum centrifuge for 30 min. After reduction with $10 \mathrm{mM}$ DTT in $25 \mathrm{mM}$ ammonium bicarbonate for $30 \mathrm{~min}$ at $55{ }^{\circ} \mathrm{C}$, the samples were alkylated with 55 $\mathrm{mM}$ IAA in $25 \mathrm{mM}$ ammonium bicarbonate for $20 \mathrm{~min}$ in the dark. Finally, samples were digested with $12.5 \mathrm{ng} / \mathrm{mL}$ sequencing grade trypsin in $25 \mathrm{mM}$ ammonium bicarbonate ( $\mathrm{pH} 8.5$ ) for at least $6 \mathrm{~h}$ at $37^{\circ} \mathrm{C}$.

MALDI-TOF/TOF MS Identification of Peptide Mixtures and Database Search. Tryptic peptide analyses were performed using an Applied Biosystems 4700 Proteomics Analyzer mass spectrometer (Applied Biosystems, Framingham, MA) equipped with a $355 \mathrm{~nm}$ nitrogen laser and operated in reflectron positive ion mode as previously reported (15). Briefly, the digested tryptic peptide samples were premixed with a $5 \mathrm{mg} / \mathrm{mL} \mathrm{CHCA} \mathrm{matrix} \mathrm{solution} \mathrm{and} \mathrm{dissolved} \mathrm{in} 50 \%$ ACN with $0.1 \%$ formic acid. MALDI-TOF/TOF MS detection and MS/ 


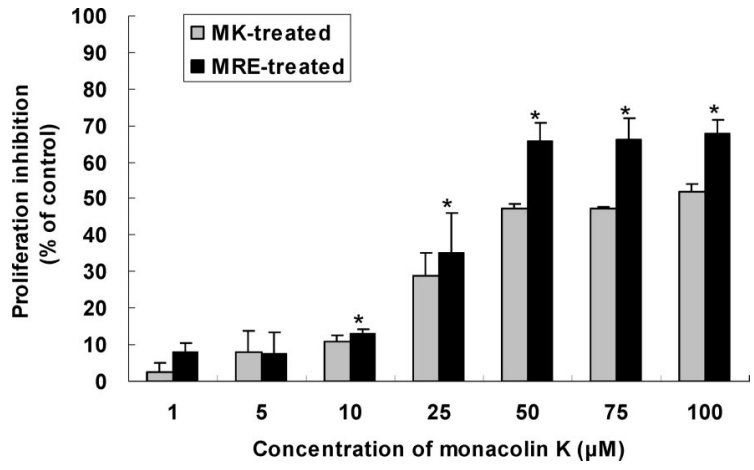

Figure 1. Effects of monacolin $\mathrm{K}(\mathrm{MK})$ and Monascus-fermented red mold rice extract (MRE) treatments on the proliferation of Caco-2 cells. Cells were treated with MK and MRE at the indicated concentrations of MK for $24 \mathrm{~h}$ (in the MRE treatment, the expressed doses of MRE usage are the MK concentrations in the MRE). Cell proliferation inhibition was assessed by MTT assay as described in Materials and Methods. The data shown are the means (percentage of control) \pm the standard error of the mean from three independent experiments. An asterisk indicates the values in the MRE-treated group at each MK concentration that were significantly different from those of the MK-treated group (Student's $t$ test; $P<0.05$ ).

MS sequencing of isopeptides were conducted in reflector mode. The indicated collision cell pressure was increased from $4 \times 10^{-8} \mathrm{mbar}$ (no collision gas) to $6.6 \times 10^{-7} \mathrm{mbar}$. At a resolution above 10000 in MS mode, accurate mass measurement ( $<50 \mathrm{ppm}$ ) of the monoisotopic isopeptide signals was possible. The MS and MS/MS spectrum data of tryptic peptides obtained from MALDI-TOF/TOF were used to search for protein candidates in SwissProt and/or NCBI databases using MASCOT. We determined that a protein was correctly identified if the search results satisfied the following criteria: (i) protein is from the correct species (Homo sapiens source), (ii) peptide mass tolerance of $50 \mathrm{ppm}$, (iii) $\mathrm{MS} / \mathrm{MS}$ ion mass tolerance of $0.25 \mathrm{Da}$, (iv) modifications were considered (Cys as $S$-carbamidomethyl derivative and Met in oxidized form), and (v) allowing for one missed cleavage site.

\section{RESULTS}

The MTT Reduction and DNA Fragmentation Analysis on Caco-2 Cells after MK and MRE Exposure. Comparisons of the cytotoxic effects of MK and MRE on Caco- 2 cells were performed using a MTT reduction assay. Following in vitro treatment of the cells with increasing concentrations of MK $(1-100 \mu \mathrm{M})$ and MRE (containing 1-100 $\mu \mathrm{M} \mathrm{MK}$ ) for $24 \mathrm{~h}$, the results showed that cell proliferation was inhibited in a dosedependent manner after MK and MRE exposure and, for each MK treatment level, the antiproliferative effects between both groups revealed significant differences with a MK level of 10 $\mu \mathrm{M}(P<0.05)$ (Figure 1). In a comparison of $\mathrm{IC}_{50}$ values (concentration causing 50\% inhibition of cell growth), the MREtreated group showed a stronger antiproliferative activity with an $\mathrm{IC}_{50}$ of $38 \mu \mathrm{M}$ MK than the MK-treated group $\left(\mathrm{IC}_{50}=53\right.$ $\mu \mathrm{M} \mathrm{MK}$ ) (the $\mathrm{IC}_{50}$ values were based on the linear regression calculation of Figure 1). Moreover, the MK-treated and MREtreated groups both induced the apoptotic characteristic of DNA fragmentation in Caco-2 cells (Figure 2). However, the MKand MRE-induced ladder patterns of DNA fragments in Figure 2 were not produced in a completely dose-dependent manner, probably due to necrotic cell death. In addition, after exposure to MK $(50 \mu \mathrm{M})$ and MRE (containing $50 \mu \mathrm{M} \mathrm{MK}$ ) for $24 \mathrm{~h}$, observed through an inverted light microscope (IX 70, Olympus, Tokyo, Japan), the morphological changes of the cells revealed

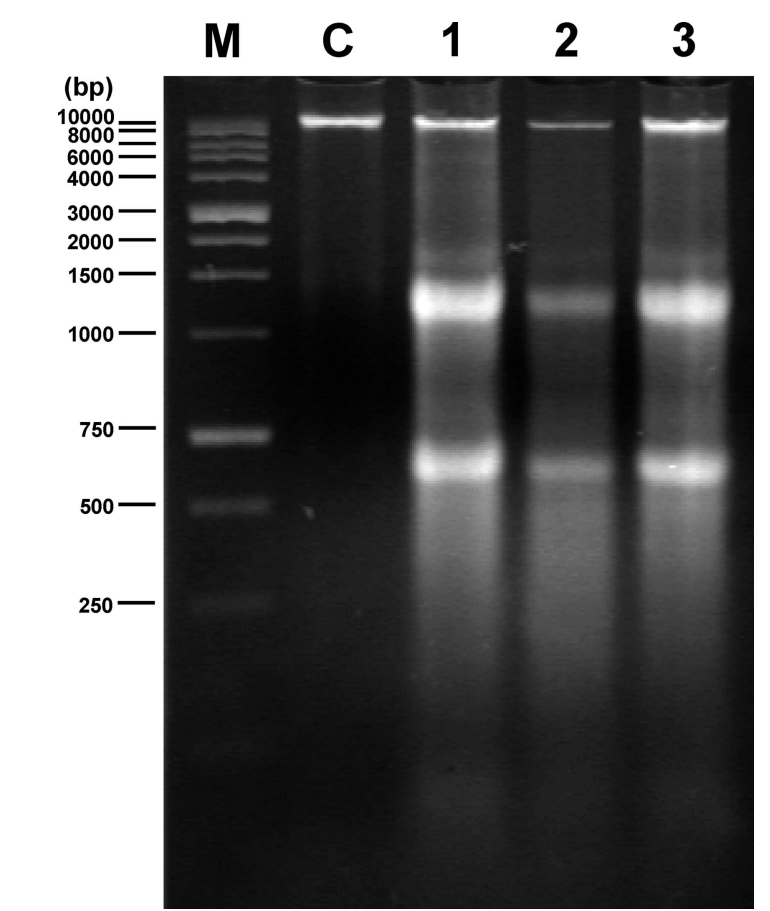

Figure 2. DNA fragmentation induced in Caco-2 cells after exposure to MK and MRE treatments for $24 \mathrm{~h}$ : lane M, 100 bp DNA ladder size maker; lane $\mathrm{C}$, control untreated cells; lane 1, $25 \mu \mathrm{M} \mathrm{MK}$; lane 2, $75 \mu \mathrm{M} \mathrm{MK}$; and lane $3, \mathrm{MRE}$ (containing $75 \mu \mathrm{M} \mathrm{MK}$ ). DNA fragmentation was analyzed by $1.5 \%$ agarose gel electrophoresis and staining with ethidium bromide. The experiment was repeated three times with similar results.

both cell shrinkage and cytoplasmic vaculation features (data not shown), which were similar to the MK-induced Caco-2 cell features in the previous study (12).

Protein Prefractionation, Separation, and Identification. To evaluate the proteome changes induced by MRE treatment in Caco-2 cells, comparison of 2-DE separation and identification of proteins extracted from the untreated control cells and the cells with MRE treatment (the concentrations of MK, ankaflavin, and monascorubrin in the MRE treatment were 50 $\mu \mathrm{M}, 32.3 \mu \mathrm{g} / \mathrm{mL}$, and $65.7 \mu \mathrm{g} / \mathrm{mL}$, respectively) for $24 \mathrm{~h}$ was performed. To increase the number of proteins identified in a proteome, protein prefractionation techniques, prior to 2-DE analysis, are being used progressively more frequently (16). Prefractionation of cellular proteins into subcellular cytoplasmic and membrane proteins in a proteome analysis was previously reported (16). This method is known to enhance protein resolution, which in turn improves 2-DE results in terms of image quality and the number of protein observed. In this work, prefractionation of cellular protein extracts into an enrichedmembrane protein preparation and an enriched-cytoplasmic protein preparation was carried out prior to 2-DE separation. 2-DE protein separation was performed in nonlinear $13 \mathrm{~cm}$ 2-DE gels with a $\mathrm{p} I$ range of 4-7 and an $M_{\mathrm{r}}$ range of 14-97 kDa. In this work, to ensure that identical proteins in different gels were recognized as being identical in the image registration, the reference gel consisted of a representative set of spots generated from three repeated registered gel images of the control or the MRE-treated cells and was used to compare each sample. 2-DE gel maps of Caco-2 cells from the enriched-cytoplasmic and enriched-membrane protein preparations are illustrated in Figure 3. After the spot densities of the protein spots were compared in the control and MRE-treated samples, 56 protein spots with statistically significant differences $(P<0.05)$ were cut and analyzed by MALDI-TOF/TOF MS. Identified proteins are 

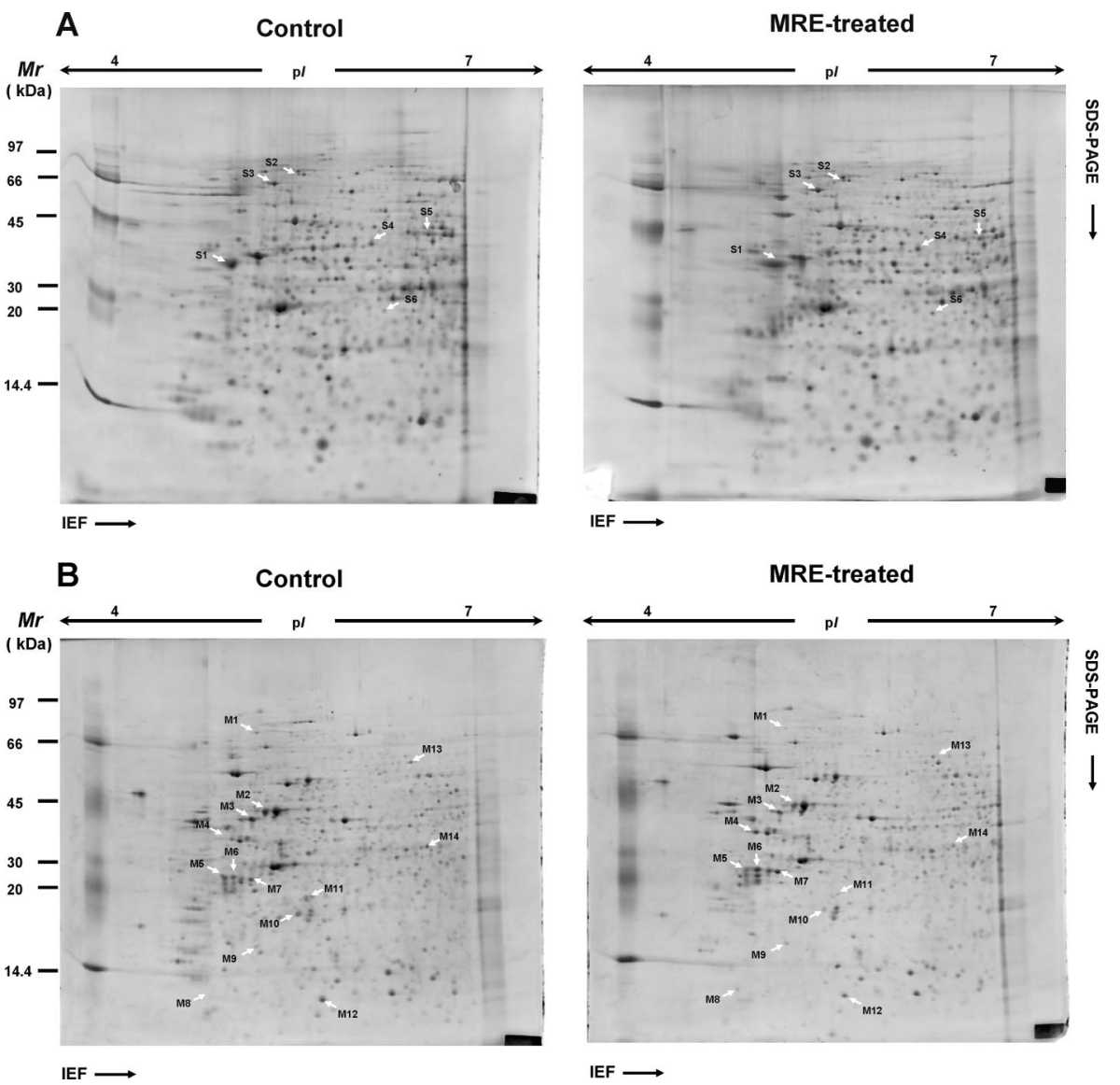

Figure 3. Comparative 2-DE gel analyses of enriched-cytoplasmic $(\mathbf{A})$ and enriched-membrane $(\mathbf{B})$ proteins of Caco-2 cells derived from the untreated control and a Monascus-fermented red mold rice extract (MRE, containing $50 \mu \mathrm{M} \mathrm{MK}, 32.3 \mu \mathrm{g} / \mathrm{mL}$ ankaflavin, and $65.7 \mu \mathrm{g} / \mathrm{mL} \mathrm{monascorubrin}$ ) treatment for $24 \mathrm{~h}$. The protein extracts $(300 \mu \mathrm{g} / 350 \mu \mathrm{L})$ were displayed across a $13 \mathrm{~cm}$ IPG strip (pH 4-7) in the first dimension and a 10\% vertical SDS-PAGE gel in the second dimension, which was stained with Sypro Ruby. Isoelectric points $(\mathrm{p} /)$ and molecular masses $\left(M_{\mathrm{r}}\right)$ are marked on the horizontal and vertical axes, respectively. Protein spots marked on the maps with arrows and numbers represent the 20 identified proteins analyzed with PDQuest. Details of the proteins are given in Table 1.

highlighted and numbered on the protein reference map shown in Figure 3. In the 2-DE protein gels from the enrichedmembrane preparation, 14 proteins, for which a positive identification could be made using peptide mass fingerprints, matched known proteins. Unexpectedly, of the 14 proteins, only three were known to be located in the membrane (17) (Table 1), while 11 were cytosolic and nuclear contaminants. Here, we suggest that some other modifications are necessary to further minimize the amount of cytosolic and nuclear contaminants, such as an extra wash of the enriched-membrane pellet. In this work, the categories of proteins identified included a highly conserved heat shock protein, a caspase protein precursor, tumor suppressors, cancer biomarkers, a transcriptional regulator, and a GTP-binding protein.

Proteome Response to the MRE Treatment. To examine the deregulated expression of these identified proteins in response to the MRE treatment of Caco-2 cells, a comparison of the identified protein contents between the control and MREtreated samples was performed using PDQuest program-aided analysis. In this work, from the 56 protein spots cut for MALDITOF/TOF analysis, a total of 20 proteins were identified. Of the 20 protein spots identified, 13 were downregulated in the MRE-treated samples (Table 1). These included the chaperone protein heat shock protein 70 (HSP70), five tumor biomarkers [S100 calcium-binding protein A9 (S100A9), clusterin-associated protein $1(\mathrm{CLU})$, protein kinase $\mathrm{C} \varepsilon$ type $(\mathrm{PKC}-\varepsilon)$, matrilysin (MMP-7), and type I cytoskeletal 10 (CK-10)], upstream binding factor 1 (UBF-1), ATP synthase subunit $\beta$ (ATPase $\beta$ ), and interferon regulatory factor 8 (IRF-8). However, several downregulated proteins, such as phosphoglyceromutase and IRF-8, exhibited an only 1.6-fold change in their level of expression. In comparison, seven identified proteins, including caspase-3 precursor (Casp-3 precursor), two tumor suppressors [N-chimaerin (NC) and calponin-2 (CNN)], ATP-dependent RNA helicase DDX4 (DEAD box protein 4, RH), 6-phosphofructo-2-kinase (PFK), tripartite motif-containing protein 73 (TRIM), and glial fibrillary acidic protein (GFAP), revealed upregulation in the MRE-treated samples.

\section{DISCUSSION}

In the literature, at least three active components, including MK (lovastatin), monascorubrin, and ankaflavin, of Monascusfermented red mold rice have been reported to have an antiproliferative effect against tumor cells $(10,11)$. However, the biological response of tumor cells to Monascus-fermented red mold rice treatment has not yet been characterized. Monacolin $\mathrm{K}$ is currently available for use as an effective anticancer therapeutic and functions by blocking the mevalonate biosynthesis pathway, inducing suppression of cancer growth. However, our current observation revealed that the $\mathrm{IC}_{50}$ value of the MRE-treated group was lower than the corresponding value of the MK-treated group (Figure 1). This indicated that some other antiproliferative action independent of MK may occur in 
Table 1. List of Identified Protein Spots of 2-DE Gel Analyses of Enriched-Cytoplasmic and Enriched-Membrane Proteins of Caco-2 Cells with Differential Expression between the Untreated and MRE-Treated Cells

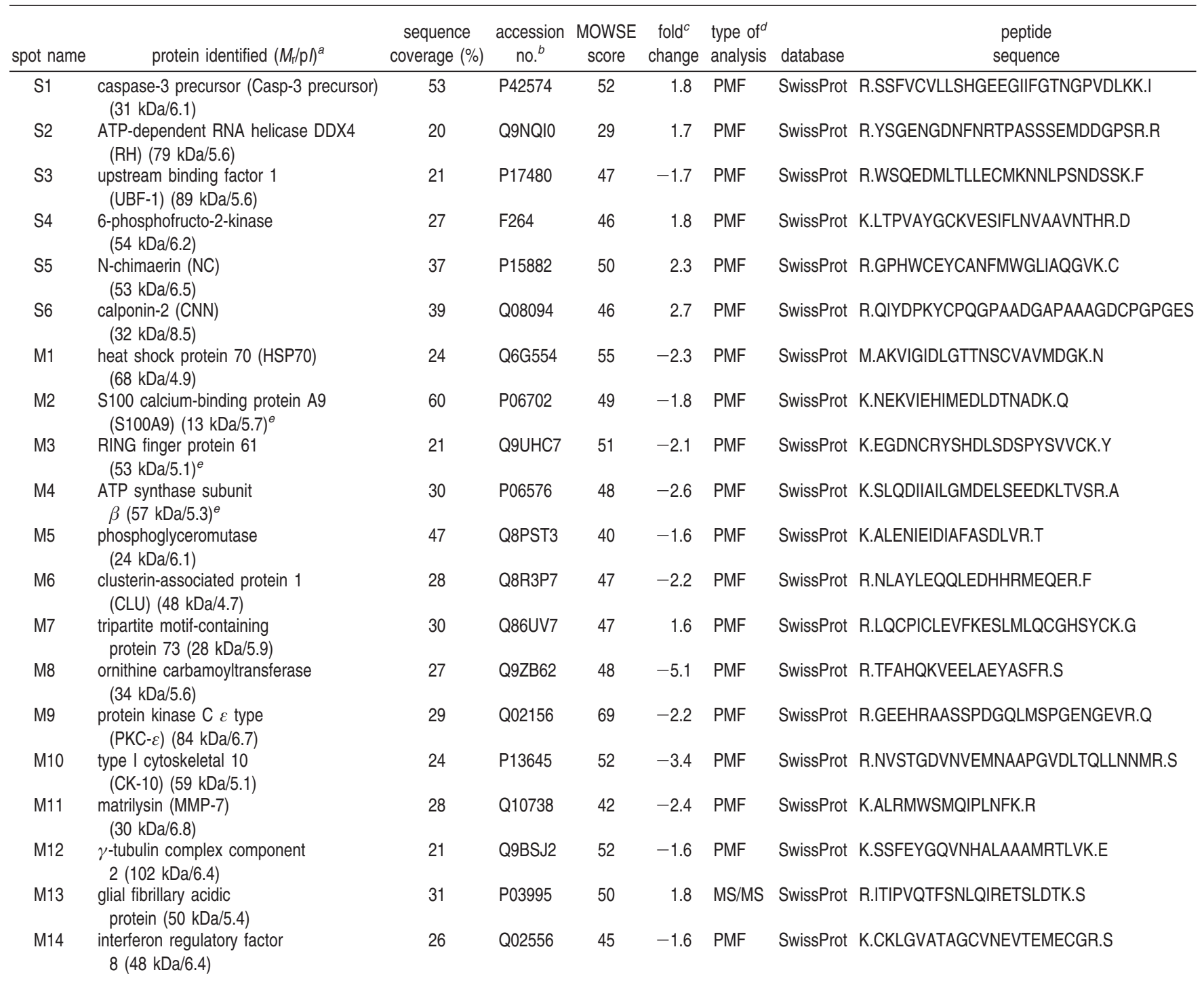

${ }^{a}$ Theoretical molecular mass $\left(M_{\mathrm{r}}\right)$ of the matched protein and theoretical $\mathrm{p} /$ of the matched protein in the database (the theoretical $M_{\mathrm{r}}$ and $\mathrm{p} /$ values are based on the SwissProt database). ${ }^{b}$ SwissProt accession number. ${ }^{c}$ The fold change of the significantly altered expression in each protein spot is determined by comparing each spot mean value (from triplicate experiments) with the corresponding mean value of the control and testing the expression change using Student's $t$ test. $P$ values of $<0.05$ were considered to be statistically significant. ${ }^{d}$ Proteins identified by using MALDI-TOF/TOF MS through PMF or MS/MS. ${ }^{e}$ Located in the membrane.

the Caco-2 cells during the MRE treatment. In the development of Monascus-fermented red mold rice into a functional anticancer health food, comprehensive and in-depth research of the mechanism of the cytotoxic effects on tumor cells should be performed. Because the mucosal absorption and transepithelial kinetics of nutrients and lipophilic compounds were evaluated using Caco-2 epithelial colorectal adenocarcinoma cell line to assess the bioavailability and absorption efficiency in rats (18), we used the well-established in vitro Caco-2 cell line as the model system for MRE treatment to discern the cytotoxic effect of the Monascus extract at the proteome level.

In this work, two tumor markers, CLU and MMP-7, coupled together with HSP70 were seen to be co-downregulated in the MRE-treated cells (Table 1). The HSPs are highly conserved and ubiquitous molecules that constitute an essential defense mechanism for various environmental damages (19). HSP70 is known to be a potent antiapoptotic HSP, and it may participate in carcinogenesis and modulate tumor cell proliferation and survival through the regulation of apoptotic pathways (20). Moreover, CLU, acting as a molecular chaperone, is known to play a role in the aggressiveness of a tumor and is a prominent candidate biomarker for cancers (21). CLU can inhibit cellular apoptosis by interfering with Bax activation in mitochondria (22). Interestingly, hand in hand, HSP70 has also been reported to block apoptosis by hindering translocation of Bax and its insertion into the mitochondrial membrane, thereby preventing mitochondrial membrane permeabilization and the release of cytochrome $c$ (23). After MRE treatment, the treated cells showed DNA fragmentation characteristic of apoptosis (Figure 2), and the downregulated expression of CLU and HSP70 appeared to act with correlation and synergism to affect the treated cells. Additionally, MMP-7, a proteolytic enzyme, is exclusively produced by cancer cells and has critical implications for tumor growth and progression (24). A recent study has reported that the level of MMP-7 expression correlates significantly with the level of HSP70 expression in squamous cell carcinomas (25). Considering the fact that HSP70 is an inhibitor of apoptosis, the downregulation of CLU and MMP-7 and their positive correlation with HSP70 decreased their level of expression during MRE treatment in the cells which may reflect 


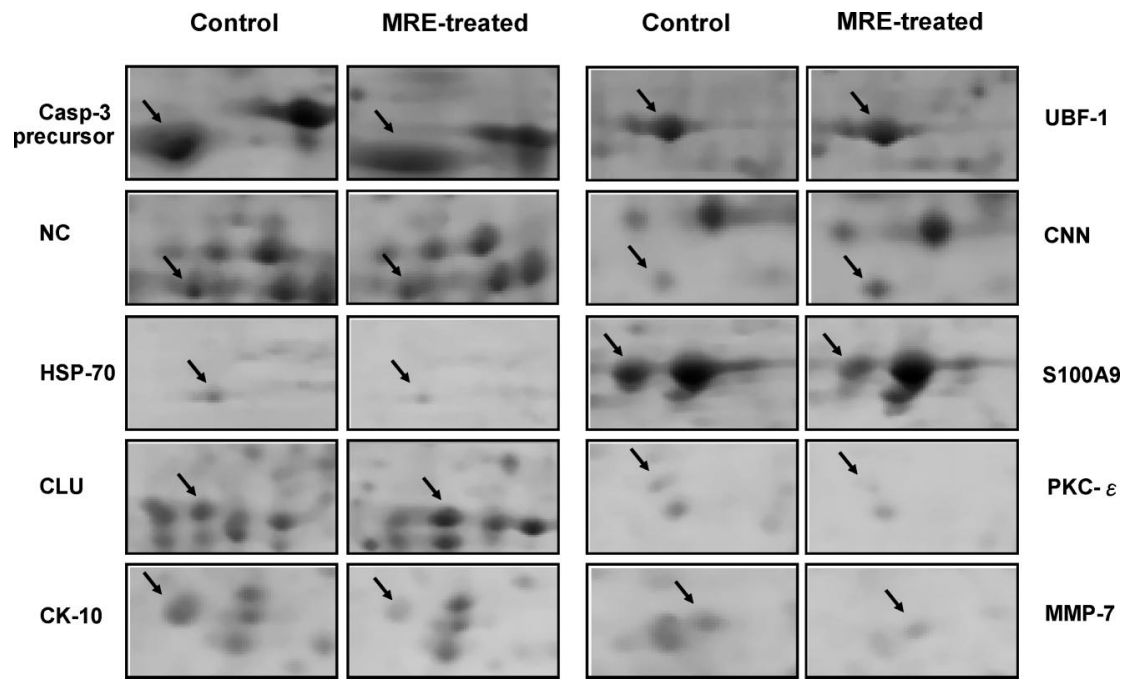

Figure 4. Enlarged view of the detailed alteration patterns of the 10 representative protein spots from 2-DE gel maps in Figure 3 (differentially expressed between the untreated and MRE-treated Caco-2 cells).

the fact that the induction of the cytotoxic effect in the MREtreated cells is a multistep process.

Even more interesting is the fact that, in the MRE-treated group, Casp-3 precursor, two tumor suppressors ( $\mathrm{NC}$ and $\mathrm{CNN}$ ), and RH were cooperatively upregulated in opposition to HSP70 downregulation. On the other hand, two cytokeratin-related proteins (CK-10 and S100A9) revealed downregulated expression in the MRE-treated cells. In the literature, activation of caspases is a biochemical hallmark of apoptosis (26). Casp-3 is a major effector caspase that plays a critical role in the apoptotic cascade (27). In the apoptotic mitochondrial pathway, DNA damage and other cellular stresses induce changes in mitochondrial membrane permeability and the release of cytochrome $c$ into the cytosol (27). This, in turn, activates Casp-9 during the formation of the apoptosome, which is composed of cytochrome $c$, Casp-9, and Apaf-1 (apoptotic protease activating factor-1) $(26,27)$. Activated apical caspases from either pathway are able to activate the effector Casp-3. However, HSP70 has been shown to bind directly to Apaf-1, thereby preventing the recruitment of procaspase- 9 to the apoptosome and inhibiting apoptosis downstream of the release of cytochrome $c$ and the activation of Casp-3 $(23,28)$. Interestingly, RH is known to interact with the general translation initiation factor eIF2 and plays a unique role in cellular growth regulation (29). The proapoptotic function of eIF 2 phosphorylation is directly coupled to mitochondrial apoptosis regulation via translational repression of antiapoptotic Bcl-2 family protein MCL-1 (30). A growing body of evidence suggests that loss of eIF2 phosphorylation reduces the level of activation of Casp-3 and -9 and delays apoptosis (30). RH overexpression may enforce mitochondrial apoptosis initiation in the MRE-treated cells via regulation of eIF2 phosphorylation. On the other hand, our observation revealed that HSP70 was downregulated during the MRE treatment, and this would lead to Bax activation, which, in turn, would undergo translocation to the mitochondria in response to cell death stimuli. Therefore, in this work, MRE-induced cytotoxicity in the Caco-2 cells was thought to be involved in HSP70-mediated modulation at the pre- and post-mitochondrial levels.

In addition, the MRE-induced upregulated expression of two tumor suppressors ( $\mathrm{NC}$ and $\mathrm{CNN}$ ) is implicated in cytoskeletal regulation (31). NC is known to exhibit its tumor suppressor functions in the in vivo suppression of cytoskeleton reorganization and transformation in hepatocellular carcinoma (32).
Likewise, $\mathrm{CNN}$ is an actin filament-associated regulatory protein, involved in modifying cytoskeleton function and in cytokinesis (33). Interestingly, in contrast, two cytokeratinrelated oncologic diagnostic markers (CK-10 and S100A9) simultaneously revealed downregulation in the MRE-treated cells. S100A9 is known to be involved in the $\mathrm{Ca}^{2+}$-dependent regulation of the assembly or disassembly of cytokeratin in epithelial cells $(34,35)$, which is correlated with the organization of cytoskeletal filaments. A growing body of evidence indicates that cytokeratin expression reflects tumor cell activity (36). In the literature, cytokeratins, such as CK-8, -10 , and -18 , have been reported to be downregulated and degraded during apoptosis of human cholangiocarcinoma cells $(37,38)$ and cleaved by caspases, resulting in the reorganization of intermediate filaments during epithelial cell apoptosis $(39,40)$. In the MRE-induced cytotoxicity in the Caco-2 cells, the resulting HSP70-mediated activation of Casp-3 suggests the existence of an amplification loop for a cascade of cytokeratin degradation. Apparently, in this work, the upregulation of $\mathrm{NC}, \mathrm{CNN}$, and Casp-3 precursor, together with the downregulation of CK-10 and S100A9, may reflect the ability of the MRE-treated cells to program morphological changes with the cytotoxic effect, resulting in cell shrinkage and nuclear fragmentation in the cells.

Another interesting finding in this work was the co-downregulation of PKC- $\varepsilon$ and UBF-1 together with HSP70 downregulation in the MRE-treated cells. PKC- $\varepsilon$, identified as an oncogene, is known as an active regulator of the ERK cascade pathway and the $\mathrm{Rb}$ hyperphosphorylation signaling pathway in LNCaP cells (41). Hyperphosphorylation of $\mathrm{pRb}$ that results in the release of E2Fs from the E2F-pRb complex is essential for the rapid growth of tumor cells (42). However, several studies indicated that HSP70 hydrolysis of ATP was indeed found to be necessary for the release of E2Fs from $\mathrm{pRb}$ and to ensure E2F-dependent transcriptional activation $(43,44) . \mathrm{Rb}$ protein is known to play a pivotal role in the negative control of the cell cycle and in tumor progression (45). Furthermore, UBF-1, as a target for screening anticancer drugs, is known to be one of the proteins that regulate the activity of RNA polymerase I, which, in turn, regulates rRNA (rRNA) transcription (46). Accumulating evidence indicates that $\mathrm{Rb}$ expression is implicated in the regulation of UBF-1-stimulated transcriptional activation $(46,47)$. UBF-1 upregulated in hepatocellular carcinoma is related to the survival of cancer cells (48). UBF-1 is an auxiliary factor which stimulates transcription by acting 
as both a transactivator and an antirepressor (46). The observed UBF-1 downregulation may reflect a reduction in the level of UBF-1-dependent transcription of rRNA gene expression in the MRE-treated cells. Here, in the MRE-treated Caco-2 cells, we suggest a HSP70-mediated cytotoxic effect that occurs via inhibition of $\mathrm{Rb}$ expression in the regulation of antiproliferative action in cells.

In this work, we used two-dimensional gel-based proteomics to compare the protein profiles and identify differently expressed proteins between the MRE-treated Caco- 2 cells and the control. A number of tumor-associated proteins, including two tumor markers (CLU and MMP-7), two tumor suppressors (NC and $\mathrm{CNN})$, and an oncogene (PKC- $\varepsilon$ ), were detected with altered expression, corresponding to a complicated multistep process implicated in the MRE treatment of Caco-2 cells. Moreover, the observed upregulation of two tumor suppressors (NC and $\mathrm{CNN}$ ) and the downregulation of three $\mathrm{Rb}$-related proteins (HSP70, PKC- $\varepsilon$, and UBF-1) with Casp-3 precursor overexpression may reflect the involvement of $\mathrm{Rb}$ - and HSP70mediated cytotoxicity in the MRE-treated Caco- 2 cells. As stated above, to date at least three antiproliferative active components (MK, ankaflavin, and monascorubrin) in Monascus-fermented red mold rice have been described. MK targets HMG-CoA reductase, but the mechanisms of the antiproliferative effects of monascorubrin and ankaflavin in tumor cells remain unclear. However, several statin-induced antiproliferation mechanisms in tumor cells, including cell cycle G1 arrest and caspasedependent and -independent apoptosis pathways, have been reported (49). In our previous work, the MK-induced antiproliferative effect in Caco- 2 cells was involved in alterations of the expressions of redox-related proteins, CKs, and energy metabolism-related proteins (12). Accordingly, compared to the MRE-induced antiproliferative action involving the altered expression proteins, including tumor-associated proteins, and HSP70- and Rb-related proteins, we suggested that, excluding $\mathrm{MK}$, the other active components may also play a significant functional role in the antiproliferative effect in Caco-2 cells. In addition, compared to that of the MK-treated group, the decrease in the $\mathrm{IC}_{50}$ value of the MRE-treated group may signify a synergistic interaction of the active components in Monascusfermented red mold rice with respect to the cytotoxic effect against Caco- 2 cells. Overall, the resulting data identifying a number of differentially expressed tumor-associated proteins may provide clues about the understanding of the underlying mechanism of cytotoxicity induced by Monascus-fermented red mold rice. However, further studies are needed to investigate the therapeutic use of Monascus-fermented red mold rice as a natural anticancer agent in animals.

\section{ABBREVIATIONS USED}

ACN, acetonitrile; Casp-3 precursor, caspase-3 precursor; CHAPS, 3-[(3-cholamidopropyl)dimethylammonio]-1-propanesulfonate; CHCA, $\alpha$-cyano-4-hydroxycinnamic acid; CK-10, type I cytoskeletal 10; CLU, clusterin-associated protein 1; CNN, calponin-2; DTT, dithiothreitol; IAA, iodoacetamide; HEPES-KOH, $N$-(2-hydroxyethyl)piperazine- $N$-(2-ethanesulfonic acid), potassium salt; HSP70, heat shock protein 70; MK, monacolin K; MMP-7 precursor, matrilysin precursor; MRE, Monascus-fermented red mold rice extract; NC, N-chimaerin; S100A9, S100 calcium-binding protein A9; SDS, sodium dodecyl sulfate; $\mathrm{PKC}-\varepsilon$, protein kinase $\mathrm{C} \varepsilon$ type; $\mathrm{PMSF}$, phenylmethanesulfonyl fluoride; $\mathrm{Rb}$, retinoblastoma protein; TFA, trifluoroacetic acid; UBF-1, upstream binding factor 1 .

\section{ACKNOWLEDGMENT}

We gratefully thank Cheng-Chung Liao from The Institute of Biochemistry, National Yang Ming University, for technical assistance with MALDI-TOF/TOF MS.

\section{LITERATURE CITED}

(1) Hajjaj, H.; Blanc, P. J.; Groussac, E.; Goma, G.; Uribelarrea, J. L.; Loubiere, P. Improvement of red pigment/citrinin production ratio as a function of environmental conditions by Monascus ruber. Biotechnol. Bioeng. 1999, 64, 497-501.

(2) Endo, A.; Hasumi, K. Biochemical aspect of HMG CoA reductase inhibitors. Adv. Enzyme Regul. 1989, 28, 53-64.

(3) Hajjaj, H.; Blanc, P.; Groussac, E.; Uribelarrea, J.; Goma, G.; Loubiere, P. Kinetic analysis of red pigment and citrinin production by Monascus ruber as a function of organic acid accumulation. Enzyme Microb. Technol. 2000, 27, 619-625.

(4) Wang, J. J.; Shieh, M. J.; Kuo, S. L.; Lee, C. L.; Pan, T. M. Effect of red mold rice on antifatigue and exercise-related changes in lipid peroxidation in endurance exercise. Appl. Microbiol. Biotechnol. 2006, 70, 247-253.

(5) Wang, I. K.; Lin-Shiau, S. Y.; Chen, P. C.; Lin, J. K. Hypotriglyceridemic effect of Anka (a fermented rice product of Monascus sp.) in rats. J. Agric. Food Chem. 2000, 48, 3183-3189.

(6) Duncan, R. E.; El-Sohemy, A.; Archer, M. C. Statins and cancer development. Cancer Epidemiol., Biomarkers Prev. 2005, 14, 1897-1898.

(7) Mackay, D. J.; Hall, A. Rho GTPases. J. Biol. Chem. 1998, 273, 20685-20688.

(8) Hippenstiel, S.; Kratz, T.; Krull, M.; Seybold, J.; von EichelStreiber, C.; Suttorp, N. Rho protein inhibition blocks protein kinase $\mathrm{C}$ translocation and activation. Biochem. Biophys. Res. Commun. 1998, 245, 830-834.

(9) Rao, S.; Porter, D. C.; Chen, X.; Herliczek, T.; Lowe, M.; Keyomarsi, K. Lovastatin-mediated G1 arrest is through inhibition of the proteasome, independent of hydroxymethyl glutaryl-CoA reductase. Proc. Natl. Acad. Sci. U.S.A. 1999, 96, 7797-7802.

(10) Yasukawa, K.; Takahashi, M.; Yamanouchi, S.; Takido, M. Inhibitory effect of oral administration of Monascus pigment on tumor promotion in two-stage carcinogenesis in mouse skin. Oncology 1996, 53, 247-249.

(11) Su, N. W.; Lin, Y. L.; Lee, M. H.; Ho, C. Y. Ankaflavin from Monascus-fermented red mold rice exhibits selective cytotoxic effect and induces cell death on Hep G2 cells. J. Agric. Food Chem. 2005, 53, 1949-1954.

(12) Lin, W. Y.; Song, C. Y.; Pan, T. M. Proteomic analysis of Caco-2 cells treated with monacolin K. J. Agric. Food Chem. 2006, 54, 6192-6200.

(13) Yu, C. C.; Lee, C. L.; Pan, T. M. A novel formulation approach for preparation of nanoparticulate red mold rice. J. Agric. Food Chem. 2006, 54, 6845-6851.

(14) Teng, S. S.; Feldheim, W. The fermentation of rice for anka pigment production. J. Ind. Microbiol. Biotechnol. 2000, 25, 141146.

(15) Lin, W. Y.; Chang, J. Y.; Tsai, P. C.; Pan, T. M. Metabolic protein patterns and monascorubrin production revealed through proteomic approach for Monascus pilosus treated with cycloheximide. $J$. Agric. Food Chem. 2007, 55, 5559-5568.

(16) Ho, E.; Hayen, A.; Wilkins, M. R. Characterisation of organellar proteomes: A guide to subcellular proteomic fractionation and analysis. Proteomics 2006, 6, 5746-5757.

(17) Weber, J.; Muharemagic, A.; Wilke-Mounts, S.; Senior, A. E. F1F0-ATP synthase. Binding of delta subunit to a 22-residue peptide mimicking the N-terminal region of alpha subunit. J. Biol. Chem. 2003, 278, 13623-13626.

(18) Konishi, Y.; Hitomi, Y.; Yoshida, M.; Yoshioka, E. Absorption and bioavailability of artepillin $\mathrm{C}$ in rats after oral administration. J. Agric. Food Chem. 2005, 53, 9928-9933.

(19) Morimoto, R. I. Cells in stress: Transcriptional activation of heat shock genes. Science 1993, 259, 1409-1410. 
(20) Jolly, C.; Morimoto, R. I. Role of the heat shock response and molecular chaperones in oncogenesis and cell death. J. Natl. Cancer Inst. 2000, 92, 1564-1572.

(21) Lau, S. H.; Sham, J. S.; Xie, D.; Tzang, C. H.; Tang, D.; Ma, N.; Hu, L.; Wang, Y.; Wen, J. M.; Xiao, G.; Zhang, W. M.; Lau, G. K.; Yang, M.; Guan, X. Y. Clusterin plays an important role in hepatocellular carcinoma metastasis. Oncogene 2006, 25, 12421250.

(22) Zhang, H.; Kim, J. K.; Edwards, C. A.; Xu, Z.; Taichman, R.; Wang, C. Y. Clusterin inhibits apoptosis by interacting with activated Bax. Nat. Cell Biol. 2005, 7, 909-915.

(23) Garrido, C.; Brunet, M.; Didelot, C.; Zermati, Y.; Schmitt, E.; Kroemer, G. Heat shock proteins 27 and 70: Anti-apoptotic proteins with tumorigenic properties. Cell Cycle 2006, 5, 25922601.

(24) Ii, M.; Yamamoto, H.; Adachi, Y.; Maruyama, Y.; Shinomura, Y. Role of matrix metalloproteinase-7 (matrilysin) in human cancer invasion, apoptosis, growth, and angiogenesis. Exp. Biol. Med. 2006, 231, 20-27.

(25) Weber, A.; Hengge, U. R.; Stricker, I.; Tischoff, I.; Markwart, A.; Anhalt, K.; Dietz, A.; Wittekind, C.; Tannapfel, A. Protein microarrays for the detection of biomarkers in head and neck squamous cell carcinomas. Hum. Pathol. 2007, 38, 228-238.

(26) Salvesen, G. S.; Dixit, V. M. Caspases: Intracellular signaling by proteolysis. Cell 1997, 91, 443-446.

(27) Zou, H.; Li, Y.; Liu, X.; Wang, X. An APAF-1•cytochrome c multimeric complex is a functional apoptosome that activates procaspase-9. J. Biol. Chem. 1999, 274, 11549-11556.

(28) Stankiewicz, A. R.; Lachapelle, G.; Foo, C. P.; Radicioni, S. M.; Mosser, D. D. Hsp70 inhibits heat-induced apoptosis upstream of mitochondria by preventing Bax translocation. J. Biol. Chem. 2005, 280, 38729-28739.

(29) Johnstone, O.; Lasko, P. Interaction with eIF5B is essential for Vasa function during development. Development 2004, 131, 41674178.

(30) Fritsch, R. M.; Schneider, G.; Saur, D.; Scheibel, M.; Schmid, R. M. Translational repression of MCL-1 couples stress-induced eIF2 $\alpha$ phosphorylation to mitochondrial apoptosis initiation. J. Biol. Chem. 2007, 282, 22551-22562.

(31) Jaffe, A. B.; Hall, A. Rho GTPases in transformation and metastasis. Adv. Cancer Res. 2002, 84, 57-80.

(32) Ching, Y. P.; Wong, C. M.; Chan, S. F.; Leung, T. H.; Ng, D. C.; Jin, D. Y.; Ng, I. O. Deleted in liver cancer (DLC) 2 encodes a RhoGAP protein with growth suppressor function and is underexpressed in hepatocellular carcinoma. J. Biol. Chem. 2003, 278, 10824-10830.

(33) Morgan, K. G.; Gangopadhyay, S. S. Invited review: Cross-bridge regulation by thin filament-associated proteins. J. Appl. Physiol. 2001, 91, 953-962.

(34) Leukert, N.; Vogl, T.; Strupat, K.; Reichelt, R.; Sorg, C.; Roth, J. Calcium-dependent tetramer formation of S100A8 and S100A9 is essential for biological activity. J. Mol. Biol. 2006, 359, 961972

(35) Goebeler, M.; Roth, J.; van den Bos, C.; Ader, G.; Sorg, C. Increase of calcium levels in epithelial cells induces translocation of calcium-binding proteins migration inhibitory factor-related protein 8 (MRP8) and MRP14 to keratin intermediate filaments. Biochem. J. 1995, 309 (Part 2), 419-424.
(36) Barak, V.; Goike, H.; Panaretakis, K. W.; Einarsson, R. Clinical utility of cytokeratins as tumor markers. Clin. Biochem. 2004, 37, 529-540.

(37) Schutte, B.; Henfling, M.; Kolgen, W.; Bouman, M.; Meex, S.; Leers, M. P.; Nap, M.; Bjorklund, V.; Bjorklund, P.; Bjorklund, B.; Lane, E. B.; Omary, M. B.; Jornvall, H.; Ramaekers, F. C. Keratin $8 / 18$ breakdown and reorganization during apoptosis. Exp. Cell Res. 2004, 297, 11-26.

(38) Ku, N. O.; Liao, J.; Omary, M. B. Apoptosis generates stable fragments of human type I keratins. J. Biol. Chem. 1997, 272, 33197-33203.

(39) Sgorbissa, A.; Benetti, R.; Marzinotto, S.; Schneider, C.; Brancolini, C. Caspase- 3 and caspase- 7 but not caspase- 6 cleave Gas 2 in vitro: Implications for microfilament reorganization during apoptosis. J. Cell Sci. 1999, 112 (Part 23), 4475-4482.

(40) Kothakota, S.; Azuma, T.; Reinhard, C.; Klippel, A.; Tang, J.; Chu, K.; McGarry, T. J.; Kirschner, M. W.; Koths, K.; Kwiatkowski, D. J.; Williams, L. T. Caspase-3-generated fragment of gelsolin: Effector of morphological change in apoptosis. Science 1997, 278, 294-298.

(41) Wu, J.; Wong, W. W.; Khosravi, F.; Minden, M. D.; Penn, L. Z. Blocking the Raf/MEK/ERK pathway sensitizes acute myelogenous leukemia cells to lovastatin-induced apoptosis. Cancer Res. 2004, 64, 6461-6468.

(42) Gaubatz, S.; Lindeman, G. J.; Ishida, S.; Jakoi, L.; Nevins, J. R.; Livingston, D. M.; Rempel, R. E. E2F4 and E2F5 play an essential role in pocket protein-mediated G1 control. Mol. Cell 2000, 6, 729-735.

(43) Garimella, R.; Liu, X.; Qiao, W.; Liang, X.; Zuiderweg, E. R.; Riley, M. I.; Van Doren, S. R. Hsc70 contacts helix III of the J domain from polyomavirus $\mathrm{T}$ antigens: Addressing a dilemma in the chaperone hypothesis of how they release E2F from $\mathrm{pRb}$. Biochemistry 2006, 45, 6917-6929.

(44) Sheng, Q.; Denis, D.; Ratnofsky, M.; Roberts, T. M.; DeCaprio, J. A.; Schaffhausen, B. The DnaJ domain of polyomavirus large $\mathrm{T}$ antigen is required to regulate $\mathrm{Rb}$ family tumor suppressor function. J. Virol. 1997, 71, 9410-9416.

(45) Giacinti, C.; Giordano, A. RB and cell cycle progression. Oncogene 2006, 25, 5220-5227.

(46) Meraner, J.; Lechner, M.; Loidl, A.; Goralik-Schramel, M.; Voit, R.; Grummt, I.; Loidl, P. Acetylation of UBF changes during the cell cycle and regulates the interaction of UBF with RNA polymerase I. Nucleic Acids Res. 2006, 34, 1798-1806.

(47) Hannan, K. M.; Hannan, R. D.; Smith, S. D.; Jefferson, L. S.; Lun, M.; Rothblum, L. I. Rb and p130 regulate RNA polymerase I transcription: $\mathrm{Rb}$ disrupts the interaction between UBF and SL1. Oncogene 2000, 19, 4988-4999.

(48) Derenzini, M.; Trere, D.; Pession, A.; Montanaro, L.; Sirri, V.; Ochs, R. L. Nucleolar function and size in cancer cells. Am. J. Pathol. 1998, 152, 1291-1297.

(49) Kong, J. Y.; Rabkin, S. W. Cytoskeletal actin degradation induced by lovastatin in cardiomyocytes is mediated through caspase-2. Cell Biol. Int. 2004, 28, 781-790.

Received for review July 23, 2007. Revised manuscript received September 6, 2007. Accepted September 7, 2007.

JF072197L 